\title{
There's just huge anxiety: ontological security, moral panic, and the decline in young people's mental health and well-being in the UK
}

\author{
Jo Bell, Marie Reid, Judith Dyson, Annette Schlosser, Tim Alexander \\ Faculty of Health Sciences, University of Hull, Hull, UK
}

\begin{abstract}
This study aims to critically discuss factors associated with a recent dramatic rise in recorded mental health issues amongst UK youth. It draws from interviews and focus groups undertaken with young people, parents and professionals. We offer valuable new insights into significant issues affecting young people's mental health and well-being that are grounded in their lived experiences and in those who care for and work with them. By means of a thematic analysis of the data, we identified an increase in anxiety related to: future orientation, social media use, education, austerity, and normalization of mental distress and self-harm. We apply the notion of ontological security in our interpretation of how socio-cultural and political changes have increased anxiety amongst young people and consequent uncertainty about the self, the world and the future, leading to mental health problems. There are also problems conceptualizing and managing adolescent mental health, including increased awareness, increased acceptance of these problems, and stigmatisation. We relate this to the tendency for moral panic and widespread dissemination of problems in a risk society. In our conclusion, we highlight implications for future research, policy and practice.
\end{abstract}

Correspondence: Jo Bell, Faculty of Health Sciences, University of Hull, Cottingham Road, Hull, HU6 7RX, UK.

Tel.: +44.0.1482.464687.

E-mail: j.bell@hull.ac.uk

Acknowledgements: the authors would like to express their sincere thanks to all of the young people, parents/carers, professionals, schools and organisations who helped to make this project possible.

Key words: Young people; Mental health; Well-being; Ontological security; Moral panic; Lived experiences.

Contributions: JB, study concept and design, data acquisition, data analysis and interpretation, manuscript drafting; MR, study concept and design, data analysis and interpretation, manuscript drafting; JD, study concept, data acquisition, checked interpretations, edited manuscript; AS, study concept and design, data acquisition, checked interpretations, edited manuscript; TA, study concept and design, data acquisition, checked interpretations, edited manuscript.

Conflict of interest and funding: this research project was funded by Hull NHS Clinical Commissioning Group, UK. The authors report grants from Hull Clinical Commissioning Group during the conduct of the study. The sponsors played no role in the design and conduct of the research project, nor in the preparation, review, or approval of the manuscript

Received for publication: 3 April 2019.

Revision received: 20 August 2019.

Accepted for publication: 20 August 2019.

This work is licensed under a Creative Commons Attribution NonCommercial 4.0 License (CC BY-NC 4.0).

${ }^{\circ}$ Copyright: the Author(s), 2019

Licensee PAGEPress, Italy

Qualitative Research in Medicine \& Healthcare 2019; 3:87-97

doi:10.4081/qrmh.2019.8200

\section{Introduction}

Over recent years in the UK, there has been a marked increase in the reporting and diagnosis of mental health problems in young people, along with an increased awareness of these issues amongst the public, health and social work practitioners, and policy makers. In surveys, more young people report experiencing difficulties related to their mental health today than 30 years ago including, particularly, reports of deliberate self-harm..$^{1,2}$ According to Earle, ${ }^{3}$ the number of young people attending emergency departments due to psychiatric and related conditions has more than doubled between 2010 and 2015 (p. 1), as has the number of referrals made to Child and Adolescent Mental Health Services (CAMHS). Demand for specialist services is growing and, as of 2016, child and adolescent services were, on average, turning away nearly a quarter of children referred to them for treatment. ${ }^{4,5}$ Most recent figures relating to the mental health of children and young people in England in 2017 indicate that one in eight 5-19 year olds had a mental disorder. ${ }^{6}$ These data identify emotional disorders as the most common mental health issue for 11-16 year olds.

Concurrently, there has been a swell in mainstream media commentary on the rise of mental health related problems amongst young people (including depression, anxiety and deliberate self-harm) with speculation about why this is happening. ${ }^{7-17}$ Cumulatively, these observations, variously couched in the rhetoric of epidemic and crisis, suggest that something very disturbing is happening with blame attributed to a range of variables. ${ }^{10}$ However, evidence to support the reasons for such a dramatic increase is lacking and mental health is usually discussed as if it was based on uncontested objective diagnoses of 
conditions belonging to individual people, rather than distress resulting from interaction with social forces.

Today's young people are living in more stressful times. ${ }^{18}$ It is arguable that by absolute criteria they have materially easier and physically less stressful lives than previous generations, but this does not appear to have reduced their mental stress or the psychological and social consequences of strain outlined above. As material conditions have improved, psychosocial conditions have become more complicated and demanding. The transition from childhood to adulthood has become long, gradual (indeed hence the term young person), complex, and may take as long as 15 years. ${ }^{19}$ During this liminal period, young people tend to experience ambiguity about what lies ahead including diverse, often longer, educational choices and a lack of certainty about their future employment, home ownership, and the formation of intimate relationships.

Fifty years ago, a 16-year-old in the UK could leave school, go to work in local industry, get married, obtain independent housing, and raise children by age 25 . Today, such a life course is relatively unusual and young people are faced with many choices: University? Who to have sex with? Who to live with and when? Where to live? How to earn a living, which rarely involves a durable vocation begun before age 20 and ending on retirement. Health promotion and protection is another relatively new way of offering choice rather than simple conformity, as people are offered a myriad of advice about how to manage their lifestyles to optimise well-being and benefit society and the environment. Young people perhaps have never had it so good in terms of choice and opportunity. However, the very plethora of choices is stressful because of the need to make those choices and because with choice comes a very wide awareness of the opportunities, resources and personal characteristics of others. More choice means more complexity, confusion, pressure and anxiety.

At the same time, one should not uncritically accept these data as evidence of the cause of the increase in mental health problems in the general population. Changes in culture and consequent definitions of mental health are confounded, with wider recognition leading to more frequent identification. Millard ${ }^{20}$ documents how self-harm became recognised as a form of behaviour separate from suicide only in the late 1970s, entering the psychiatric curriculum later and the general medical curriculum much later. Over the years emergency department staff are likely to have become more adept at recognising self-harming behaviour and patients more willing to admit to self-harm.

Additionally, concerns about young people's mental health show some of the signs of a moral panic, ${ }^{21}$ where complicated social issues are reduced to alarming statistical trends and simplistic causes of those issues are sought. Another feature of the moral panic is that the high profile and well-intentioned concern about the problem publicises it, normalises it and unwittingly encourages more people to get involved. Currently, social media are being advocated as likely explanations of young people's poor mental health. ${ }^{22}$

Thus, a number of factors and issues have been suggested to account for this sudden dramatic increase in what are accounted for in terms of mental health problems amongst young people in the UK. However, supporting evidence is lacking, and given the wide range of terminology currently being used interchangeably to describe and document young people's mental health, research in this area can be complex and challenging. We know of no existing qualitative research that focuses on the lived experiences of young people and those who work with and care for them, in this area. This paper aims to address this.

We draw from a study on the mental health and wellbeing of young people in Northern England. Our research took place in 2016 and employed a mixed methods approach using online surveys and a range of individual interviews and focus groups. Here we present and critically discuss insights into the main issues associated with the rise in mental health problems amongst young people in recent years drawn from qualitative data at the interview/focus group stage.

We apply the notion of ontological security in our interpretation of how macro level happenings impact wellbeing on micro (individual) levels. Ontological security refers to a stable state derived from a sense of continuity in regard to the events in one's life and individual experiences. ${ }^{23}$ It involves having a positive view of the self, the world and the future. Built on trust, ontological security is considered to be a precursor to generic psychological well-being. ${ }^{24,25}$ Features include constancy, privacy, an autonomous sense of self, a secure base for identity construction, a sense of mastery and control, belonging, connectedness, and certainty about the future.

\section{Materials and Methods}

\section{Setting and background}

The research took place in a North of England City, with a large rural hinterland. It has a single specialist CAMHS, plus a wide variety of relevant services sited in various ways across the community. The research originated in local practitioner and policy maker concerns that young people were not getting appropriate and timely access to mental health services. It was designed, planned and conducted with the primarily practical aim of improving access to mental health services for young people. This paper represents one set of themes derived from the qualitative data, mainly in response to questions about why young people's mental health service needs seemed to have increased. We did not set out to research the effects of the social forces discussed here on young people's mental health, but those themes were drawn out during the interview process alongside more practical issues such 
as geographical barriers to access and uncertainty about when a young person's problems were serious enough to require referral to CAMHS.

\section{Recruitment}

We undertook semi-structured in-depth individual interviews and focus groups with i) young people who had experienced problems with their mental health and who had accessed specialist services for this; ii) parents/carers of young people who had experienced problems with their mental health and who had accessed specialist services for this; iii) professionals and practitioners who work in some capacity with young people who have experienced mental health problems.

In the early stages of the project, we established a steering group of young people and consulted with a variety of professionals (e.g. Criminal Justice System, general medicine, CAMHS, schools, mental health organisations and charities) who provided us with an extensive list of contacts to invite to our professionals focus groups. We recruited young people who had experience of accessing mental health to the study via a mental health charity and a Voice and Influence worker who worked with young people in schools. In addition, we recruited via an online survey parents and carers of young people who had experienced mental health problems and who had accessed specialist services. We distributed the survey via schools and other organisations (as in above). As part of the survey, we invited respondents to take part in a face-to-face interview/focus group about their experiences of accessing mental health services for their child.

\section{Interviews}

We asked participants a range of open-ended interview questions which were designed to uncover perceived barriers and facilitators to accessing mental health services as well as the participants' experience and understanding of young people's mental health, needs of particular groups, and approaches to recognizing and working. Examples included: What do you think are the main issues that have contributed to the rise in mental health problems amongst young people in recent years? What do you think facilitates young people seeking help/what helps people access support? What do you think prevents people seeking help? We encouraged them to talk openly and to actively lead the way in discussions, prompting regularly for further explanation and detail when relevant.

In this paper we report on results from the first of these example questions, which asked of all groups of participants: What do you think are the main issues that have contributed to the rise in mental health problems amongst young people in recent years?

We obtained ethical approval for the study from the Faculty of Arts and Social Sciences Ethics Committee at the University of Hull, UK. Participants took part on the basis of anonymous, voluntary informed consent.

The total number of interviewees is shown in Table 1. We undertook a range of in depth individual interviews and focus groups including: three individual interviews (all female) and one focus group ( $\mathrm{n}=5: 1$ male, 4 female) with young people (aged between 14-19 years) who had experienced mental health problems and who had accessed mental health services; three individual interviews and one focus group ( $\mathrm{n}=2$ female) with parents of young people who had experienced mental health difficulties and who had accessed local mental health services; and three focus groups ( $n=4 ; n=4 ; n=3)$ with individuals who work with young people in a professional capacity across a variety of settings. These included: 2 youth workers (1 male, 1 female), 2 teachers (female), 4 specialist mental health workers (female), 1 general practitioner (male), 1 social worker (female), and 1 emergency services practitioner (female). On average, interviews and focus groups lasted for 60 minutes but ranged from 30-90 minutes. We did not collect data on extent of mental health difficulties experienced, or age of parents/carers and professionals. Parental consent was obtained for one 14-year-old male participant. Due to risk of identification, comments from individual participants are not specified in our findings. Instead, we attribute comments to specific groups (e.g. FG1, FG2, FG3, FGyp).

\section{Analysis}

We audio recorded interviews and focus groups, transcribed them verbatim, then removed all identifying information. We analyzed data using thematic coding and analysis to categorise data into themes relating to the specific research question. ${ }^{26,27}$ Thus, to begin with we selected all data collected in response to the question: What do you think are the main issues that have contributed to the rise in mental health problems amongst young people in recent years? As interviews and focus groups were open-ended and largely participant led, respondents often tended to go off track in conversation and would return to the theme later in the interview. Where this happened we also highlighted and extracted these data.

As a theoretically flexible approach, thematic analysis provides a way of understanding participant experiences that is consistent with, and relates back to, their lived realities..$^{27,28}$ Thematic analysis does not need the same level of

Table 1. Total number of interviewees from all three groups.

\begin{tabular}{lccc}
\hline & Individual interview & Focus group & Total \\
\hline Young people & 3 & $1(\mathrm{n}=5)$ & 8 \\
\hline Parents & 3 & $1(\mathrm{n}=2)$ & 5 \\
\hline Professionals & 0 & $3(\mathrm{n}=4 ; 4 ; 3)$ & 11 \\
& & & 24 \\
\hline
\end{tabular}


detail in the transcript as conversation or discourse analysis; there is no one way to conduct thematic analysis, and there is no one set of guidelines to follow. However, there is consensus that thematic analysis requires a rigorous account of all verbal (sometimes nonverbal) responses. ${ }^{27}$

We used the six stage approach recommended by Braun and Clarke: ${ }^{27}$ i) familiarisation of the data (through repeated listening while reading transcripts; we listened for tone to identify any incongruencies in the meaning of words, e.g. as with sarcasm), ii) generation of initial codes (our initial ideas about the data, and what was interesting about them with regard to the research question), iii) searching for themes (consideration of how different codes combined for themes), iv) reviewing themes (by reviewing themes at the level of coded data extracts and within the context of the entire data set), v) defining and naming themes (we aimed to identify the essence of what each theme was about and where possible we used participant words for naming of themes) and vi) producing the report (which we aimed to be concise, logical, and interesting with sufficient data to evidence themes identified). One author (JB) created the initial coding framework and two (MR and AS) independently coded transcripts by way of inter-rater reliability. This was an iterative process by which the framework was adjusted and recoding occurred until there was over $90 \%$ agreement between coders.

\section{Results}

When we asked about the main factors associated with the rise in mental health problems amongst young people in recent years, participants talked most about a perceived increase in anxiety. We identified this as our overarching theme. Different issues and explanatory factors (accounting for this perceived increase in anxiety) were identified across the data set, which we coded into sub-themes. These were: future orientation; damaging effects of social media; changing landscape of education; austerity and inequality; normalization of mental distress. We present these in turn below.

\section{Pressure and uncertainty about the future}

This theme attributes an increase in anxiety to the complexities of growing up in a modern changing society with competing pressures and uncertainty:

Young people can't be young people because there's too much pressure on them...our society as a whole is just a lifelong pressure and we don't seem willing to reduce it (FG1).

Young people don't have the opportunity and space to work out who they are in the world (FG2).

I think there's even more and more teens getting mental health problems... mostly the kind of depression, self-harm because the pressures in life are getting harder right now... there's more competition (young person).

Participants spoke about the negative impact of all this on young people's aspirations for the future, highlighting perceived tensions between expectation and reality as in this example:

This very broad idea that we as a society are bringing young people up with these new expectations that you can achieve anything in life, you can go where you want, do what you want, have what you want but the reality actually is not everyone can have that .... I think that's the root cause of, not just young people's mental health issues but mental health as a, as a general rule... (FG1).

This young person described her uncertainty about what the future holds:

Uncertainty about your future because it just... keeps getting worse and all... the political parties getting worse and whatever is happening, it just creates that kind of... anger... what will my future look like, it's not looking good for young people right now... obviously unemployment and things like that ... it contributes majorly to at least the start of a mental illness and obviously once something starts mentally it can quickly get worse... it's a confusing time in your life and I think having this really uncertain surrounding with wars happening ... it's just that fear...

\section{Damaging effects of social media}

Participants perceived social media use to be a major contributing factor to anxiety amongst young people. They depicted a hostile online world filled with hate, bullying, and pressure from which there is no escape:

The thing that comes mostly to mind is social media and about how that's used, and what gets seen out there and what gets tweeted and lots about hate and trolling and I think that can't help anybody's mental health (FG2).

$100 \%$ social media ... there is so much pressure on young people... online bullying... you don't have to talk to a person face to face, it's so easy to just type that thing, it's sent and everyone sees... a photo's there and everybody can see it... you literally ruined their life... (young person).

We have a huge issue with social media, we have a huge issue with pornography... we have massive problem with sexting, massive, we deal with that weekly (FG3).

Images that have been sent ... the pressure from... there is no escape... because you go home and it's still there... through Facebook ... through Snapchat ... that has a huge part to play in that. Going home and shutting the door just doesn't happen anymore (FG3).

Participants tended to think that social media practices were damaging to young people's reputation and position 
in the peer group, with implications for social development and emotional well-being. None of the participants actively dissented from this type of opinion. The prevalence of, and concerns about these issues, we argue, shifts the social norms regarding them, making the problems potentially worse, a point we return to later.

\section{Increasing school pressures}

Participants mentioned another significant change contributing to increased anxiety in young people, from their secondary schools, which over recent years have become more pressurised because they are increasingly assessed to national outcomes, such as the proportion of pupils achieving specific grades in national exams. This was perceived as having created multiple pressures and expectations:

Schools put way too much pressure on the kids... I've noticed more students now coming through saying I'm stressed... and crying, and I think that filters down obviously from us putting pressure on to them, they're getting pulled in so many different directions ... (FG1). exam pressure's huge on them because they'll feel that not only from their peers but from the teachers, from their parents.... (FG3).

These perspectives were also echoed by young people: more competition...out there for everything... obviously that's an issue for education, that it's getting so much harder, ... GCSEs... it's so difficult .... I was very anxious about my education (young person). everywhere now... schools are getting less funding, they're turning into academies and academies are focused on grades and business, it's a business rather than a school.... there's just huge anxiety.... (young person).

Professionals spoke of schools under increasing pressure to achieve better results, with constant changes and messages from Government and media that they are not good enough. Increased pressures on teachers in schools can mean teachers do not feel they have time to build relationships with pupils and to understand their difficulties: Pressure on schools and young people... to get a decent Ofsted report... the pressure that they're under, potentially can undermine how they then relate to young people and children ... I think those sort of societal norms are changing in terms of the pressure on young people (FG1).

\section{Austerity; reduced resources}

Many of the issues above relate also to economic pressures brought about by the austerity policies of UK Governments over the past decade. Participants felt that young people's services, other than schools (themselves subject to budget cuts), had vanished or become unable to function in a timely and effective fashion. Professionals spoke at length about the cumulative effects of funding cuts to health and community services for young people as the following quotes illustrate:

I think there has always been a tendency for mental health services to be at the bottom of the ladder ... when the money's handed out... they're being crucified... in terms of the cuts... since austerity (FG3). and there doesn't seem to be that... long term vision... ....(FG2).

... the youth clubs, there is a policy of them all being closed down... the long term impact of that means there's nobody there for the young people... there's nowhere for them to go... (FG3).

Respondents were vocal on the impact of these changes on young people, particularly with regard to reduced access to mental health services:

...that whole idea of the waiting times as well... an hour, if you are struggling mentally with mental health... feels like six months, so eighteen weeks... when you are at a really low point is just unachievable in your mind... (FG3).

...services are being cut, families are feeling under pressure... Purses are being pinched in all directions... It's a really confusing place to be... people have got a heck of a lot to be angry about and confused (FG2).

\section{Normalisation of mental distress and self-harm}

A final theme derived from our data indicates increased tolerance towards mental health problems. Participants felt that young people nowadays tend to feel comfortable talking about mental health and self-harm and they believed that social attitudes have changed:

I feel like there's an increase in numbers because... more people are telling people... being more open about it (FGyp).

The role of social media in this attitudinal shift was also recognised:

I think it's spoken about a lot more because... things

like... Twitter have got bigger, but back then... it was a lot more sort of hush hush... whereas now it's spoken about, people know it happens (FGyp).

Some respondents suggested a consequence of increased openness is that more young people are engaging in, or admitting to, self-harming behaviour and identifying as having mental health problems because they regard them as acceptable or interesting:

They're extremely open talking about it.... so they've tried it... just sort of like almost following the crowd really...they tell each other about it, and so it dawns on them that it is an option... they feel stressed and they don't know what to do and they think oh maybe that works...(parent).

This professional extended the idea by suggesting selfharm is not only acceptable but appealing for some young people as a way of gaining popularity:

it's almost... for want of a better word... it's a cool 
thing to do..., when I first started, we would see girls and some boys, coming in very covered up... very discreetly sneaking in... and feeling quite embarrassed, whereas now we see girls.... scars on show... almost as something that they're quite proud of in a sense... asking for stitches when it's just not necessary... really unusual from what it used to be like... I don't know how else to describe it really but, that it's... almost like a fashion (FG1).

This view was also reflected on by some young people as illustrated in the following extract:

... recently there's been a lot of people... like competing against each other, like saying oh yeah, my anxiety's worse than yours because I have panic attacks and social anxiety or whatever, and then it's like... cool to be mentally disturbed if you know what I mean ... (FGyp).

Participants recognised the role of media in raising awareness of young people's mental health as suggested above. In these extracts, young people attributed social media to both the popularisation and spread of self-harm:

With social media... so many people see it online and... might think oh I need to fit in ... with everyone seeing it online and it being such a big thing now and a lot more people talk about it in school and it's just a lot more known about... I see it... every day down my newsfeed ... people sharing it ... (FGyp).

You'll often find on Facebook...... people cutting themselves and saying do you still think I'm beautiful (FGyp).

I think a lot of it comes with celebrity influence ... a lot more celebrities are sort of coming out and saying look I suffer with this... sort of like trying to aspire, it's almost like a fashion trend (FGyp).

\section{Discussion}

Participants said that young people find their lives pressurised and the future uncertain and unpredictable (as suggested by Morgan et al.). ${ }^{18}$ Pressures can be amplified by social media and reduced resources for mental health and other services. Self-harm and mental health problems are more acceptable, or recognised, ways of coping with pressures than they used to be. Participants felt that austerity, hence budget cuts, and increased assessment of schools had made matters worse.

Our findings chime broadly with existing literature on the massive transformation of contemporary society that Castells ${ }^{29}$ called Network Society and its impact on individual mental health. ${ }^{24}$ In this age of rapid social transformations, globalization, and the segmentation of society, we suggest, young people face a landscape of competition, academic stress, bullying, and relational, life course, well-being, and identity worries.

Moreover, there is evidence of similar patterns and trends in other Western developed nations suggesting this is not a phenomenon limited to the UK. For example, increasing rates of mental disorders among young people over time have been highlighted in Australia and the US (Eckersley), ${ }^{30}$ the Netherlands, Norway, and Hungary (Sweeting et al.) ${ }^{31}$ and Canada (Malla et al.). ${ }^{32}$ Eckersley $^{30}$ discussed the adverse impact of societal changes on young people's mental health in Western developed nations, arguing for a greater understanding of existential and relational factors and a shift in emphasis to cultural explanations.

\section{Living in a world under pressure: applying the lens of ontological security}

A recent report by the Children's commissioner for England on public spending on children suggested that spending on youth services and prevention has been cut by $60 \%$ over the past decade. ${ }^{33}$ The impact of this on young people was discussed by Cummins, ${ }^{34}$ who argued that austerity and associated policies have combined to increase the overall burden of mental distress and marginalization. The impact of this has also been felt by schools, who have had to make up for cuts to young people's health and social care services. And, at the same time, changes in the education system towards reductionist notions of performance and economic rationalism (where funding is contingent on exam success) ${ }^{35}$ have added to this burden. Our analysis highlighted a number of ways in which these related issues have impacted negatively on young people. In particular, our interpretation of the increased academic pressure that our participants spoke of, we argue, is made more poignant by Torrance ${ }^{36}$ who argued that the use of assessment to raise educational standards have been greater in the UK than anywhere else in the world.

Thus, we suggest, austerity combined with increased academic pressure, rising expectations and competition, both demoralises and provokes anxiety amongst young people, contributing to pressure at an individual level. Marsh $^{37}$ and Mills ${ }^{38}$ discuss how austerity policies create harsh, hostile, and unkind environments. Participants felt that in practice this applied especially to young people living with mental health problems. At an individual level, the psychological impact of this is anger, anxiety, despair, powerlessness. The psychological impact of austerity was also discussed by McGrath et al. ${ }^{39}$ who argued that austerity policies have psychological costs such as instability, insecurity, and powerlessness, which have been shown to increase mental health problems. Austerity makes people sick by psychologically and physically wearing them out (such as in waiting weeks or months for an appointment with a mental health service). It is probable that austerity has resulted in a widening gap between the ideal of young people's mental health service provision and its reality, which generates further pressure and stress amongst young people who seek help. Insecurity and powerless- 
ness are key austerity ailments that have a damaging psychological impact, destabilising ontological security amongst those affected by eroding a sense of predictability and trust.

However, the vocabulary that participants used to describe the atmosphere of the changing world for young people, such as confusion, fear, anxiety, pressure, anger, have, for a long time, been associated with development at this stage of life. For example, the seminal work of G. Stanley Hall in 1904 characterizes adolescence as a time of storm and stress. ${ }^{40} \mathrm{So}$, are things really much different now?

Contemporaneously with the increase in public austerity in the UK has come exponential growth in social media use, especially by young people and increasingly on mobile devices so that social media can be accessed anywhere at any time. According to the Royal Society for Public Health, ${ }^{22}$ this clearly has deleterious effects on mental health, which are widely attributed to social media's purposive design to encourage frequent use, the potential for invidious comparisons of oneself, and the possibility that social and aesthetic blunders, including inept use of social media, can be disseminated widely, rapidly, and permanently. ${ }^{22}$ These make every day social life more stressful, as suggested by our participants, particularly for people who have weaker self-esteem. However, social media also reflect and perhaps help to exaggerate the nature of contemporary society towards individualism, consumerism, and overemphasis on constructing social networks on the basis of people's superficial characteristics.

Walgrave et al..$^{41}$ discussed the role of social media in the lives of young people, including mental health, and suggested that social networking sites represent a new way for young people to explore their identities. In the last decade, social media have transformed the methods by which we are social, the geographical reach of who we can be social with, and the pressures that come with reliance on the opinions of others. It has extended the range of feedback from close friends, to acquaintances and peers who are acquired as a currency of popularity (i.e. how many friends have you got on Facebook or followers on Instagram?). These remote friends widen the pool of people to compare oneself to, but with relatively weak social bonds. Remote friends may not be sources of support in times of trouble and, unlike close friends, it is not easy to check on their representations of self on social media.

Goffman, ${ }^{42}$ in his theory of self-presentation and impression management, noted the great psychological effort required for continuous self-monitoring, as individuals try to manage the impressions that other people form of them by presenting themselves in ways that they perceive will be favourable. This effort can be conscious or subconscious and fuelled by awareness of our place as actors on the stage of life, where our every move is scrutinised and judged by an on-looking audience. Perhaps this difficulty is compounded by social networking practices: as the number of people in the social network expands, so does the size (and gaze) of the imaginary audience and the impression management and self-presentation work required to respond to it. Moreover, the endemic use of smartphones means that it can be difficult to ever go backstage (as Goffman described it) because one's every word and action can potentially be broadcast by nearby friends or family members.

Boyd ${ }^{43}$ argues that imagined audiences and collapsed contexts are par for the course in the social life of networked young people. Collapsed contexts occur when people are forced to grapple with otherwise unrelated social contexts that are rooted in different norms and demand different social responses. As in Ogburn's ${ }^{44}$ cultural lag, where the psychosocial ability of humans to adapt is outpaced by sociocultural change, or, in this instance, socio-technological change, it becomes complicated. Young people need to manipulate social media to develop their identities but need experience and skills to navigate what unfolds. ${ }^{43}$

Because of the sheer rapidity of social media and the frequency with which people view them, young people's social worlds can be chronically collapsed. They can send and receive communications of concern any time, in any social context and whatever their current emotional and physical state. Moreover, not responding to social media communications, or not responding in a timely manner, can itself be perceived as a form of, usually negative, communication. A final challenge is that even if one elects to opt out of social media temporarily, they are likely to be surrounded by others who are communicating, possibly about what that person is doing (hence... there is no escape... because you go home and it's still there... through Facebook ... through Snapchat...). All of this, we suggest, poses problems for the immediate presentation of self, and genuine difficulties regarding the authenticity of self, so it is likely to hinder the development of social and personal identity and damage self-esteem. Thus, collapsed contexts can destabilise ontological security and erode one's sense of reliability and continuity in everyday life. ${ }^{24}$

A further point here relates to online communication, which is different from offline communication in a number of important ways. The online disinhibition effect refers to the invisibility, anonymity, and fantasy elements of online communication, which frees users to behave in much more disinhibited and shocking ways than would ever occur in a face-to-face encounter, providing an outlet for otherwise hidden dimensions of self. ${ }^{45,46}$ These transformations, we argue, help to explain the hate and trolling referred to by participants. For example, gossip and rumours have historically spread in the school environment through word of mouth. However, what is new is the way social media alters and amplifies these social situations, creating new social dynamics and the potential for drama with more and more people joining in..$^{43}$ The online disinhibition effect allows people to say these things precisely 
because they can get away with it and because it doesn't feel real. As Cassidy et al. ${ }^{47}$ suggest, there is no capacity for the perpetrator to witness the victim's response. And yet it feels real to those at the receiving end because of the magnified gaze of the imaginary audience and the fact that one's esteem and validation of identity is so strongly tied to it. Thus, the huge issues to be dealt with on a daily basis (described by our professional respondents), and the perception on the part of those young people who are the subject of the drama that their lives have been ruined. Their reputations have been sullied at a time when sense of self is fundamentally linked to the appraisal of others for approval, self-esteem, acceptance, and validation.

This argument is consistent with a breadth of research internationally, which has shown adolescents' intense use of social media to be correlated with low self-esteem; $; 2,48$ ${ }^{51}$ decreased subjective well-being, ${ }^{22,52-55}$ lower body image satisfaction, ${ }^{48}$ and anxiety and depression..$^{56-58}$

Whatever the explanation, the tricky issue is about how to construct and negotiate identity and a secure sense of self in a networked era. Our analysis and interpretation suggests that social media has transformed the social world in which young people are growing up. At a time when identities are fragile, young people are struggling to make sense of who they are in an environment in which contexts are networked and collapsed, audiences are expanded yet invisible, lines between reality and fantasy are blurred, and anything they say or do can be taken out of context, all whilst under constant surveillance (everybody can see it) from which they feel they have no escape and no privacy ${ }^{43}$ In an era of social media then, identity work is bound to create anxiety and potentially threaten ontological security.

The unique fantasy elements along with the asynchronisation and accessibility of social media may also, we argue, be responsible for the creation of unrealistic expectations and aspirations referred to by participants through increased exposure and social comparison.$^{59}$ This, in turn, impacts mental well-being in a number of ways.

Asynchronisation refers to the editing and conscious consideration of information offered, where, for example, young people can create unrealistically idealistic profiles and images of themselves online. Accessibility refers to the opportunity to interact with a vastly increased number of people. Taken together, this means that information about the activities and profiled lives of others is amplified and exposure to it largely unconstrained. Research by Chou and Edge $^{60}$ suggests such practices can encourage negative social comparisons and the misguided perception that others' lives are happier and better than one's own. Other research has shown that spending intense periods of time ruminating over this can contribute to depressive symptoms amongst young people as well as a developing sense of inadequacy about themselves in the face of desires and aspirations, which are, for the most part, unattainable.$^{56}$ Over time, such reflection and rumination create tensions between expec- tations and reality referred to previously, and is similar to Durkheim's observations on the disturbance of equilibrium where To pursue a goal which is by definition unattainable is to condemn oneself to a state of perpetual unhappiness (cited in Jones, p. 11). ${ }^{61}$

This explanation also helps to illustrate how a mismatch between increased expectations about the future, and the reality of what can be achieved, particularly in an era of austerity, gives rise to existential anxieties, anger, and discontent. Thus, we suggest, increased social comparison via social media can lead to negative implications for identity and the future, or, in terms of ontological insecurity, an anxious relationship to being. ${ }^{62} \mathrm{Hence}$, as one respondent put it: Young people don't have the opportunity and space to work out who they are.

Finally, social media were also heavily implicated in the normalisation and popularisation of mental health and self-harm by participants in our study. Our analysis suggests that viewing self-harm related postings and re-postings on a daily basis on various social networking platforms gradually desensitises young people towards it, transforming it, in some cases, to something ubiquitous and appealing (mental illness is cool), or to something trivial. It would appear, perhaps, that attitudes towards the subject of mental health and self-harm have changed and social media have played a significant role in that. No longer a hidden issue, could an increased prevalence of self-harm be attributable, at least in part, to increased disclosure about such behaviour from young people rather than increased engagement with it? Additionally, whilst for some, self-harm might be an expression of frustration, anger, psychological pain, or a more serious mental health problem, for others it may be a way to gain popularity ( $a l$ most like a fashion), notoriety, acceptance, or understanding. For some young people, it could be identity-related (as in testing out or experimenting with aspects of the hidden or developing self), a practice made easier by the unique affordances of online social networking as discussed above.

With regard to social changes and personal choice referred to earlier, identifiable mental health problems may have become partly a matter of individual choice for some young people. Although issues such as low mood, anxiety or stress are not chosen, how and when mood fluctuations become recognised by oneself or others as problematic may be chosen. Our analysis suggests that, compared to the past, mental health issues tend to be simultaneously more recognised and more problematised.

Mental illness and self-harm have always been variously misinterpreted, misunderstood, and trivialised. So is what is being observed a greater acceptance of mental health issues, even serious ones, as being widespread amongst young people, for which there are limited helping resources in the community? Does this drive people with acute problems to become cases at a specialist service, which may be stigmatising and can lead to enduring issues? 
The suggestion is compatible with the notion of risk in modern society. Beck's ${ }^{63}$ work, for example, describes how modern society has become increasingly pre-occupied with preventing and managing risks (described as the believed expectations of catastrophes) that it has produced itself (manufactured risk). Some of these risks, according to Wimmer and Quandt, ${ }^{64}$ arise out of the inability of institutions to cope with the pace of scientific progress. They highlight how scientific experts have now become the mouthpiece through which these risks are communicated to the public and how we have come to rely on experts to solve problems. The media play a key role in the construction of risk in this way by legitimizing their reality to the public (as in the rhetoric of epidemic and crisis observed in mainstream media commentary on young people's mental health) ${ }^{64}$

Together, then, the risk society and the changing relationship between public and scientific expertise creates (and feeds) public anxiety and moral panic around the issue. Hence, the self-fulfilling consequences occur when self-harm is constructed as a risky behaviour. The tendency for moral panic and widespread rapid dissemination of problems can, in this way, be seen as a reflection of public anxiety (ontological insecurity) mirrored back onto young people.

\section{Conclusions}

Our findings and interpretation offer valuable new insights into the observed decline in the mental health and well-being of young people in recent years. They suggest that wider social changes may account for this, including in the UK: austerity, outcome driven education, ontological insecurity, and the rise of network society. These changes, we argue, impact life in general, and mental health and well-being in particular, because they facilitate uncertainty, which is inherently stressful and also leads to worry and rumination. This in turn is fuelled by being always under scrutiny and able to compare oneself to a wide variety of others, including unrealistically positive models and undesirably negative models. All of this, we suggest, leads to uncertainty about the world, the future, and the self. Thus, some fundamental features of modern society, including those that have contributed to past progress (such as education and digital technologies), now appear to be working against better (mental) health. ${ }^{30}$

Or perhaps they are transforming mental health. Whilst uncertainty, unpredictability, and precariousness may have always been part of life, we suggest they may be qualitatively different in contemporary society. Our interpretation supports the view that austerity and current educational systems create harsh and hostile environments and, in an age of social media where tensions between expectations and reality are amplified, young people's capacity to visualise a place and role for themselves in the world in the future is further compromised. Social media represent the most significant and unprecedented change in young people's lives in recent years, permeating just about every aspect of life. The impact of young people's use of these emerging technologies suggests a transformative shift in identity work for young people at a time when identities are already fragile and in a state of development. The precise nature of this shift and its consequences warrants further detailed research and investigation.

At the same time, our study cautions against uncritically accepting statistics which tell us that poor mental health is on the rise, or that all social media use is damaging. As attitudes towards the subject of mental health and self-harm have changed, we suggest, identified mental health issues have become integrated into more young people's social identities. It has become less stigmatising and shameful to self-harm, or to admit to low mood. Further research is required to understand what this means, but it does not necessarily imply that young people are unhappier and have less well-being than they used to. This is a conservative and nostalgic interpretation that ignores major improvements in young people's well-being, including more rights for young people in general. Many young people now seem less ashamed of unhappiness. The increased openness is positive, but it can clash with health and social care systems that were designed to provide interventions for diagnosable or at least recognisable disorders. New ways of conceptualizing and managing young people's mental health are required so that having low well-being for understandable reasons does not transform too readily into being diagnosed with a mental health problem.

\section{References}

1. Mental Health Foundation. Mental Health Statistics: Children and Young People. Available from: https://www.mentalhealth.org.uk/statistics/mentalhealth-statistics-children-and-young-people Accessed: August 8, 2018.

2. The Children's Society. The Good Childhood Report; 2018. Available from: https://www.childrenssociety. org.uk/sites/default/files/good_childhood_summary_20 18.pdf_Accessed: November 4, 2018.

3. Earle J. Children and Young People's Mental Health. London: British Medical Association; 2016.

4. Patalay P, Fitzsimons E. Mental ill-health among children of the new century: trends across childhood with a focus on age 14. London: Centre for Longitudinal Studies; 2017.

5. Frith E. Centre Forum Commission on Children and Young People's Mental Health: State of the Nation. London: Centre Forum; 2016.

6. NHS. Mental Health of Children and Young People in England; 2017. Available from: https://digital.nhs.uk/ 
data-and-information/publications/statistical/mentalhealth-of-children-and-young-people-in-england/ 2017/2017\#resources Accessed: January 29, 2019.

7. Bacino L. Shock figures show extent of self-harm in English teenagers; 2014. Available from: https:// www.theguardian.com/society/2014/may/21/shockfigures-self-harm-england-teenagers Accessed: May 21, 2014.

8. Tait P. Causes of growing mental health problems sit largely within schools; 2015. Available from: https:// www.telegraph.co.uk/education/educationopinion/1202 5711/Schools-largely-to-blame-for-rising-mentalhealth-issues.html Accessed: December 2, 2015.

9. Campbell D. NHS figures show shocking rise in selfharm among young; 2016. Available from: https:// www.theguardian.com/society/2016/oct/23/nhs-figures-show-shocking-rise-self-harm-young-people Accessed: October 23, 2016.

10. Bedell G. Teenage mental-health crisis: rates of depression have soared in past 25 years; 2016. Available from: https://www.independent.co.uk/life-style/health-andfamilies/features/teenage-mental-health-crisis-rates-ofdepression-have-soared-in-the-past-25-years-a6894676 .html Accessed: February 27, 2016.

11. Topping A. Two-thirds of children referred for mental healthcare in England not treated; 2017. Available from: https://www.theguardian.com/society/2017/nov/27/me ntal-healthcare-england-children-referred-gp-nottreated Accessed: November 27, 2017.

12. Sanghani R. Why are so many of Britain's teen girls struggling with mental health problems?; 2017. Available from: https://www.telegraph.co.uk/health-fitness/body/why-are-so-many-of-britains-teen-girls-stru ggling-with-mental-he/ Accessed: March 16, 2017.

13. Lepper J. Number of young people receiving mental health support rises to 240,$000 ; 2017$. Available from: https://www.cypnow.co.uk/cyp/news/2003685/number-of-young-people-receiving-mental-health-support-rises-to-240-000 Accessed: May 24, 2017.

14. Hedderwick T. Crisis in mental health care for young people; 2017. Available from: https://www.theguardian. com/society/2017/oct/24/crisis-in-mental-health-carefor-young-people Accessed: October 24, 2017.

15. McInnis K, Barrett G. Girls admitted to hospital for self-harming nearly doubles; 2018. Available from: https://www.bbc.co.uk/news/newsbeat-45082767 Accessed: August 6, 2018.

16. Silverman R. The real reason today's children are so unhappy; 2018. Available from: https://www.telegraph.co.uk/family/parenting/real-reason-todays-children-unhappy/ Accessed: February 8, 2018.

17. Wakefield J. Is social media causing childhood depression?; 2018. Available from: https://www.bbc.co.uk/ news/technology-42705881. Accessed: February 10, 2018.

18. Morgan C, Webb R, Carr M, et al. Incidence, clinical management, and mortality risk following self harm among children and adolescents: cohort study in primary care. Brit Med J 2017;359:j4351.

19. Arnett JJ. Emerging adulthood: a theory of development from the late teens through the twenties. Am Psychol 2000;55:469-80.

20. Millard C. A history of self-harm in Britain. Basingstoke: Palgrave Mcmillan; 2015.

21. Cohen S. Folk devils and moral panics: The creation of the mods and rockers. London: MacGibbon and Kee Ltd; 1972.

22. Royal Society for Public Health. Status of Mind: Social Media and Young People's Mental Health and Wellbeing. Available from: https://www.rsph.org.uk/ourwork/campaigns/status-of-mind.html. Accessed: 2018.

23. Giddens A. Modernity and self-identity: self and society in the late modern age. Cambridge: Polity Press; 1991.

24. Whitley R. Postmodernity and Mental Health. Harvard Rev Psychiat 2008;16:352-64.

25. Chase E. Security and subjective well-being: the experiences of unaccompanied young people seeking asylum in the UK. Sociol Health Illn 2013;35:858-72.

26. Flick U. An introduction to qualitative research. 5th ed. London: Sage; 2014.

27. Braun V, Clarke V. Using thematic analysis in psychology. Qual Res Psychol 2006;3:77-101.

28. Liamputtong P, Ezzy D. Qualitative research methods. 2nd ed. Oxford: Oxford University Press; 2005.

29. Castells M. The rise of the network society. Oxford: Blackwell; 1996.

30. Eckersley R. A new narrative of young people's health and well-being. J Youth Stud 2011;14:627-38.

31. Sweeting H, West P, Young R, Derr, G. Can we explain increases in young people's psychological distress over time? Soc Sci Med 2010;71:1819-30.

32. Malla A, Shah J, Iyet S, et al. Youth mental health should be a top priority for health care in Canada. Can J Psychiatry 2018;63:216-22.

33. Kelly E, Lee T, Sibieta L, Waters T. Public spending on children in England: 2000-2020. London: Institute for Fiscal Studies; 2018.

34. Cummins I. The impact of austerity on mental health services provision: a UK perspective. Int J Environ Res Public Health 2018;15:E1145.

35. Kenway J, Bullen E. Education in the age of uncertainty: an eagle's eye-view. Compare 2000;30:265-73.

36. Torrance H. Assessment of the national curriculum in England. In: Kellaghan T, Stufflebeam DL, eds. International handbook of educational evaluation. Vol 2. Dordrecht: Kluwer Academic Publishers; 2003. pp 905-928.

37. Marsh I. Suicide: the hidden cost of the financial crisis; 2014. Available from: https://www.newstatesman.com/politics/2014/08/suicide-hidden-cost-financi al-crisis Accessed: August 5, 2014. 
38. Mills C. 'Dead people don't claim': a psychopolitical autopsy of UK austerity suicides. Crit Soc Policy 2018;38:302-22.

39. McGrath L, Griffin V, Mundy E. The psychological impact of austerity: a briefing paper. Educ Psychol Res Practice 2016;2:46-7.

40. Hall GS. Adolescence: its psychology and its relations to physiology, anthropology, sociology, sex, crime, religion, and education. Vols. I \& II. New York: D. Appleton \& Co;1904.

41. Walgrave M, Ponnet K, Vanderhoven E, et al., eds. Youth 2.0: social media and adolescence. London: Springer; 2016.

42. Goffman E. The presentation of self in everyday life. New York: Anchor Books; 1959.

43. Boyd D. It's complicated: The social lives of networked teens. London: Yale University Press; 2014.

44. Ogburn WF. Social change. New York: BW. Huebsch Inc; 1922.

45. Suler J. The online disinhibition effect. Cyberpsychol Behav 2004;7:321-6.

46. Suler J. Identity management in cyberspace. J Appl Psychoanal Stud 2002;4:455-9.

47. Cassidy W, Faucher C, Jackson M. Cyberbullying among youth: a comprehensive review of current research and its implications and application to policy and practice. School Psychol Int 2013;34:575-612.

48. Gonzales AL, Hancock JT. Mirror, mirror on my Facebook wall: effects of exposure to Facebook on self-esteem. Cyberpsychol Behav Soc Netw 2011;14:79-83.

49. Raymer K. The effects of social media sites on self-esteem. Thesis Diss., Rowan University; Theses and Dissertations 2015;284. Available from: http://rdw.rowan. edu/etd/284

50. Muller KW, Dreier M, Beutel ME, et al. A hidden type of internet addiction? Intense and addictive use of social networking sites in adolescents. Comput Hum Behav 2016;55:172-7.

51. Blachnio A, Przepiorka A, Pantic I. Association between Facebook addiction, self-esteem and life satisfaction: a cross-sectional study. Comput Hum Behav 2016;55:701-5.

52. Verduyn P, Lee DS, Park J, et al. Passive Facebook usage undermines affective well-being: Experimental and longitudinal evidence. J Exp Psychol Gen 2015;144:480-8.

53. Kross E, Verduyn P, Demiralp E, et al. Facebook use predicts declines in subjective well-being in young adults. PLoS One 2013;8:1-6.

54. Best P, Manktelow R, Taylor B. Online communication, social media and adolescent well-being: a systematic narrative review. Child Youth Serv Rev 2014;41:27-36.

55. Wood MA, Bukowski WM, Lis E. The digital self: How social media serves as a setting that shapes youth's emotional experiences. Adolesc Res Rev 2016;1:163-73.

56. Feinstein RA, Hershenberg R, Bhatia V, et al. Negative social comparison on Facebook and depressive symptoms: rumination as a mechanism. Psychol Pop Media Cult 2013;2:161-70.

57. Chen W, Lee K. Sharing, liking, commenting, and distressed? The pathway between Facebook interaction and psychological distress. Cyberpsychol Behav Soc Netw 2013;16:728-34.

58. Tandoc EC Jr, Ferrucci P, Duffy M. Facebook use, envy, and depression among college students: is Facebook depressing? Comput Human Behav 2015;43:139-46.

59. Valkenburg P, Peter J. Social consequences of the internet for adolescents: a decade of research. Curr Dir Psychol Sci 2009;18:1-4.

60. Chou HT, Edge N. 'They are happier and having better lives than I am': the impact of using Facebook on perceptions of others' lives. Cyberpsychol Behav Soc Netw 2012;15:117-21.

61. Jones RA. Emile Durkheim: an introduction to four major works. Beverley Hills, CA: Sage Publications; 1986.

62. Laing RD. The divided self: an existential study in sanity and madness. London: Pelican Press; 1965.

63. Beck U. The risk society: towards a new modernity. London: Sage Publications; 1992.

64. Wimmer J, Quandt T. Living in the risk society. Journalism Stud 2006;7:336-47. 